\title{
EHMTI-0103. Errors in recognition and management are still frequent in cluster headache
}

\author{
M Sánchez del Río ${ }^{1 *}$, R Leira² ${ }^{2}$ P Pozo-Rosich ${ }^{3}$, JM Laínez $^{4}$, R Alvarez $^{5}$, J Pascual ${ }^{6}$ \\ From 4th European Headache and Migraine Trust International Congress: EHMTIC 2014 \\ Copenhagen, Denmark. 18-21 September 2014
}

\section{Introduction}

The prevalence of cluster headache $(\mathrm{CH})$ is estimated to be around $0.1 \%$ of the general population; that is most likely physicians will be consulted by patients with $\mathrm{CH}$ during their clinical practice.

\section{Aims}

To analyse the trajectory to diagnosis and information provided in a series of $\mathrm{CH}$ patients from five headache clinics in Spain.

\section{Methods}

$\mathrm{CH}$ patients were asked to fulfil an ad hoc questionnaire.

\section{Results}

Seventy-five patients (mean age 41.5 years, 67 males) completed the questionnaire. Patients had visited during an average of 4.9 years a mean of 4.6 physicians who had obtained 2.5 neuroimaging procedures per patient before getting a diagnosis of $\mathrm{CH}$. Sixty-three (84\%) had received no diagnosis (21 cases; $28 \%$ ), while 43 (57\%) had been given an average of 2.1 alternative diagnoses. Migraine, trigeminal neuralgia and sinusitis were the most frequent mistakes. After diagnosis, 55\% had subjectively received poor/very poor information on $\mathrm{CH}$. Ninety-five percent had poor or incorrect information about the nature of the disease, or acute $(70 \%)$ and preventive $(61 \%)$ treatments. Aetiology (90\%), management options (36\%) and potential adverse events of medications (29\%) were their main information demands.

\section{Conclusions}

Although $\mathrm{CH}$ is an invalidating and clinically clear-cut disorder suffered by around 1/1000 people, it is still frequently unrecognized and/or mistaken for other disorders, which calls for a better knowledge and education in the diagnosis of the main primary headaches.

No conflict of interest.

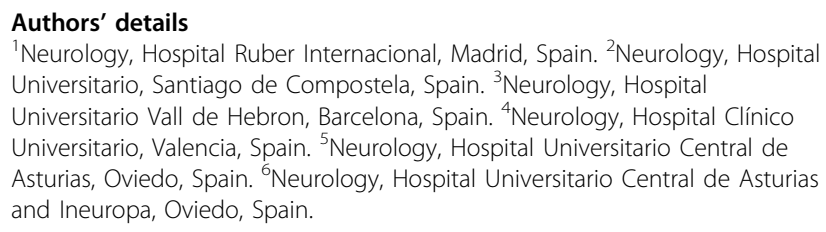

${ }^{1}$ Neurology, Hospital Ruber Internacional, Madrid, Spain. ${ }^{2}$ Neurology, Hospital Universitario, Santiago de Compostela, Spain. ${ }^{3}$ Neurology, Hospital Universitario Vall de Hebron, Barcelona, Spain. ${ }^{4}$ Neurology, Hospital Clínico Universitario, Valencia, Spain. ${ }^{5}$ Neurology, Hospital Universitario Central de Asturias, Oviedo, Spain. ${ }^{6}$ Neurology, Hospital Universitario Central de Asturias and Ineuropa, Oviedo, Spain.

Published: 18 September 2014

doi:10.1186/1129-2377-15-S1-C50

Cite this article as: del Río et al.: EHMTI-0103. Errors in recognition and management are still frequent in cluster headache. The Journal of Headache and Pain 2014 15(Suppl 1):C50.

Submit your manuscript to a SpringerOpen ${ }^{\bullet}$ journal and benefit from:

- Convenient online submission

- Rigorous peer review

- Immediate publication on acceptance

- Open access: articles freely available online

- High visibility within the field

- Retaining the copyright to your article

Submit your next manuscript at $\gg$ springeropen.com 